$13^{\text {th }}$ International Conference on AEROSPACE SCIENCES \& AVIATION TECHNOLOGY, $\boldsymbol{A S A T - 1 3 , ~ M a y ~} 26$ - 28, 2009, E-Mail: asat@mtc.edu.eg Military Technical College, Kobry Elkobbah, Cairo, Egypt Tel : +(202) 24025292 - 24036138, Fax: +(202) 22621908

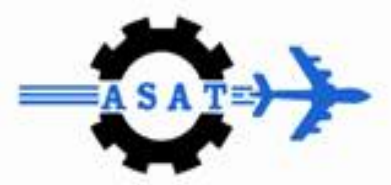

\title{
Investigation of Dynamic Performance of an Electro-Hydraulic Proportional System
}

\author{
Tamer M. Menshawy ${ }^{*}$, Mohamed A. Moghazy ${ }^{*}$, Ahmed H. Lotfy ${ }^{*}$
}

\begin{abstract}
Proportional and servo valves are used to control the velocity, or force of an actuator. In some cases, two or more parameters have to be controlled. For example, as a cylinder is extended, its velocity might be controlled. At the end of the cylinder's stroke, the servo system may be used to either position the cylinder or to control the exerted force on the work piece. In present study the dynamic performance of an electrohydraulic system, containing a proportional directional valve, has been investigated theoretically and verified experimentally. The electro-hydraulic system, under investigation, contains an electrohydraulic proportional valve which is used to control a hydraulic cylinder velocity under constant load. The electrohydraulic system consists of a hydraulic tank, a gear pump; a relief valve; a proportional directional valve; a hydraulic cylinder with vertical load; and connecting hoses. Experimental works have been carried out to measure the pump-relief valve characteristics and the pressure losses in the connecting hoses. These measured data have been curve fitted to simulate the characteristic of the pump-relief valve and the connecting hoses. A verified theoretical model of the directional proportional valve, which was previously presented and published in [Menshawy, T.M., "Investigation of Dynamic Behavior of an Electro-hydraulic Proportional System”, M.Sc. Thesis, Military Technical College, Cairo, Egypt, 2006.], has been used here. The simulation model of the hydraulic cylinder with vertical load has been carried out. All these models have been introduced within the MATLAB-SIMULINK environment in order to obtain the theoretical simulation program of the electrohydraulic system operation. The model of the electrohydraulic proportional system has been validated experimentally and has been used to investigate the performance of the system when works under different operating conditions.
\end{abstract}

Keywords: Hydraulic system; Directional control valve; Proportional valve; Solenoid; Hydraulic Control; Simulation; Modeling; Pressure Measurement; SIMULINK.

\section{Introduction}

Electro-hydraulic proportional control valves (EHPV) offer a step up in the technology of fluid power control. They move us from the relatively low-tech world of simple on-off control into a higher technological plane in which a more sophisticated valve is operated by electronics rather than just electrical switching. The advantage of this step is greater flexibility in system design and operation as well as a decrease in fluid-power circuit complexity for processes requiring multiple speed or force outputs. Because of the extreme flexibility, the combinations of functions (such as flow control and direction control in a single valve), and the rapid cycling capabilities of modern EHPVs, the applications for such valves are continuously expanding.

\footnotetext{
* Egyptian Armed Forces
} 
A proportional valve is such valve produces an output (pressure, flow) that is proportional to an electronic control input. This definition resembles that of both the solenoid valves and the servo valves, and there is a huge gap in performance and cost between these two valves. The solenoid valve is actuated or un-actuated - fully open or fully closed, with no intermediate position. Thus, it is simply an on-off valve, and its maximum frequency capability is usually $5 \mathrm{~Hz}$ or less. The servo valve, in contrast, is a continuously controlled, high frequency response device that receives commands through its electronic control system that provides a high degree of control over position, velocity, acceleration, motor rotational speed, pressure, and other factors. The servo valve could accept and accurately respond to command signals at frequencies exceeding $100 \mathrm{~Hz}$ with high accuracy because of the continuous feedback from electronic transducers. The electro-hydraulic proportional control valve is designed with actuating device (the proportional solenoid) allows the spool to be stopped at intermediate position rather than at the ends of the solenoid stroke. The associated electronics controls the spool position and offers a high degree of flexibility compared with the solenoid valve. Great evolutions have been achieved in modern proportional valves to resemble the performance of the servo valves. These evolutions involve; first a spool position feed back loop was added, next came improvements in the designs of the spools and the electronics, then came external feedback systems, higher frequency response, better, performance in accuracy, hysteresis, dead band, threshold, and other parameters. In short the proportional valves began to look more and more like to servo valves capability. These performance and control improvements carried with them increase in cost. They also blurred the distinction between servo valves and proportional valves. As a result, performance and control are no longer distinguishing criteria. Rather, physical features and manufacturing processes are the defining characteristics. For instance, proportional valves are operated by proportional solenoids, whereas servo valves are operated by torque motors. The spools in proportional valves are almost entirely machine produced, while the spools for servo valves require a great deal of manual lapping and finishing. The clearances and tolerances in servo valves are much tighter than in proportional valves. These differences in manufacturing requirements mean that the servo valve is still much more expensive than a comparably sized proportional valve.

The electro-hydraulic system, under investigation, encloses an electro-hydraulic proportional valve used to control a hydraulic cylinder velocity under constant load. The electro-hydraulic system consists of a hydraulic tank, a gear pump; a relief valve; a proportional directional valve; a hydraulic cylinder with vertical load; and all connecting hoses. The present investigation started with experimental works in order to measure the pump-relief valve characteristics and the pressure losses in connecting hoses. Also the developed transient pressure in the hydraulic cylinder chamber has been measured versus solenoid current. Next step was to manipulate the measured data of the pump-relief valve and connecting hoses by MATLAB program to curve fit and simulate their characteristics in the hydraulic system. A verified theoretical model of the directional proportional valve, which was previously presented and published in reference [4], has been used here. Then the theoretical simulation model of the hydraulic cylinder with vertical load has been carried out. . All these models have been assembled within the MATLAB-SIMULINK environment in order to obtain the theoretical simulation program of the electro-hydraulic system operation. The model of the electro-hydraulic system has been validated by the experimental results of the measured transient pressure in the hydraulic cylinder. Finally the validated model has been used to investigate the performance of the system when works under different operating conditions. 


\section{Experimental Investigations}

The experimental works have been done in the hydraulic and pneumatic laboratory of mechanical power department in MTC. The test rig has been established on a special hydraulic bench equipped with all necessary industrial hydraulic and electro-hydraulic components to build all kinds of needed circuits. A built in closed loop hydraulic power system contains a hydraulic reservoir with all its accessories equipped with a hydraulic gear pump and its relief valve. The pump discharge pipe has a shut off valve and leads to a fast connection port which permits attachment of the constructed hydraulic circuit on a perforated panel. The return line of the circuit could be connected to a fast connecting port which leads to the hydraulic reservoir.

Experimental works have been carried out to measure the following:

1. The pump-relief valve characteristics $(\mathrm{p}-\mathrm{Q})$,

2. The pressure losses in connecting hoses $(\Delta \mathrm{p}-\mathrm{Q})$,

3. The transient pressure developed in the hydraulic cylinder chamber versus solenoid current $(\mathrm{p}(\mathrm{t})$ - I).

The constructed circuit diagram of the electro-hydraulic proportional system which has been used for the present investigation is shown in Fig. (1).

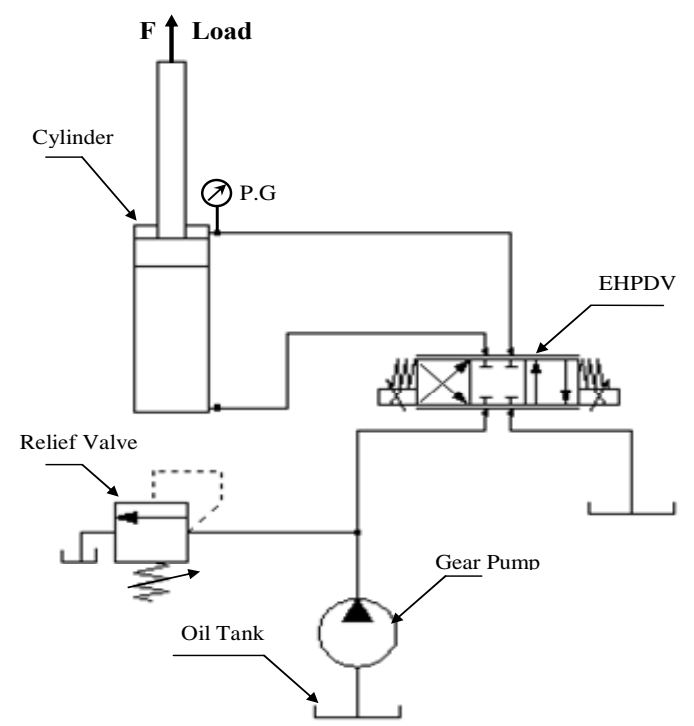

Fig. 1. Circuit diagram of electro-hydraulic proportional system

\subsection{Measurement of the hydraulic pump-relief characteristics} (pump pressure versus flow rate) at constant pump revolutions.

The experiment test rig is shown in Fig. (2). It consists of the following:

Hydraulic test bench (1), Pressure transducer attached to the pump exit (2), Relief valve (3), Display unit for read outs of pressure transducer and flow meter (4), Flow meter (5), Throttle valve and connecting hoses (6). 


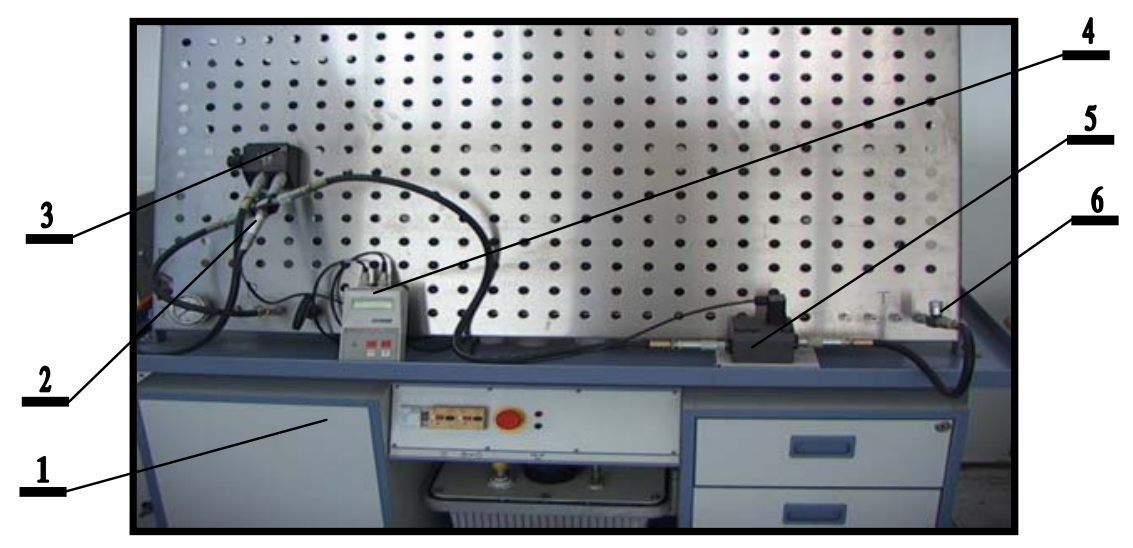

Fig. 2. Test rig of pump-relief valve characterestic measurment

\subsubsection{Measurement procedures:}

1. Adjusting the relief valve to set the maximum allowed pressure in hydraulic circuit at the value of 55 bar,

2. Setting the throttle valve at fully opening position,

3. Turning the pump on,

4. Recording the flow rate and pressure transducer readings via their display units,

5. Changing the setting position of the throttle valve and repeat step 4,

6. Repeat step 5 at different flow rates,

7. Plotting the recorded data (pump pressure versus flow rate) and performing curve fitting by MATLAB program to get the mathematical model (simulation) of the pumprelief valve characteristics.

\subsubsection{Obtained results}

Fig. (3), presents the pump-relief valve characteristics curve. The upper continuous line represents the theoretical pump flow rate. The other line represents the pump flow rate versus pump pressure.

The obtained pressure-flow rate characteristic equation is:

$$
Q_{p}=Q_{t h}-7 \cdot 10^{-13} p
$$




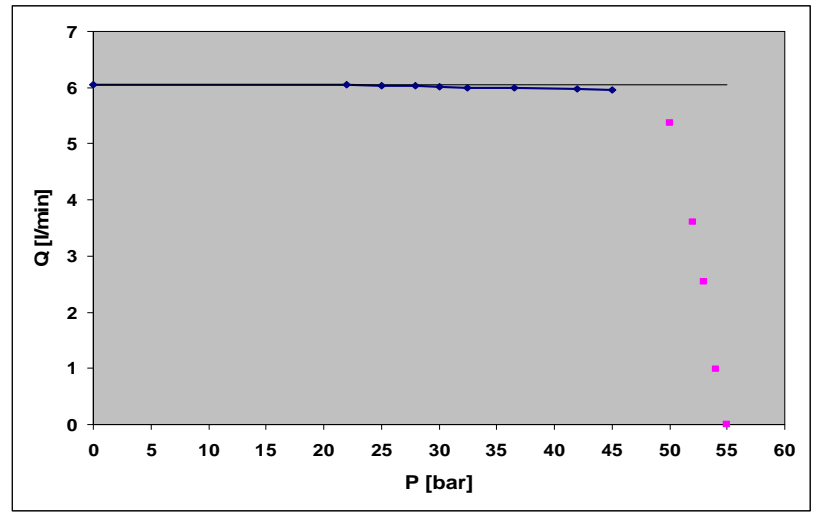

Fig. 3. Pump-relief valve characteristics

\subsection{Measurement of hydraulic losses in connecting hoses versus pump flow rate}

Two different lengths of connecting hoses have been used $(60 \mathrm{~cm}$ and $110 \mathrm{~cm})$, both are provided with quick connection ends for easy connection and disconnection of different hydraulic elements. Motion of hydraulic oil in transient conditions takes place under the action of fluid inertia, friction, and compressibility as well as driving pressure force [8]. It was difficult to consider the transient conditions of the available connecting hoses because of the existence of quick connections at both ends of the hose length which dominate the contribution of pressure losses in the measured signal. So, only steady state measurement of pressure losses has been considered here.

The experimental test rig is shown in Fig. (4). It consists of the following:

Hydraulic test bench (1), Throttle valve (2), Flow meter (3), Two pressure transducers attached to the inlet and outlet sections of the connecting hoses (4), Two display units for read outs of the pressure difference and flowrate (5).

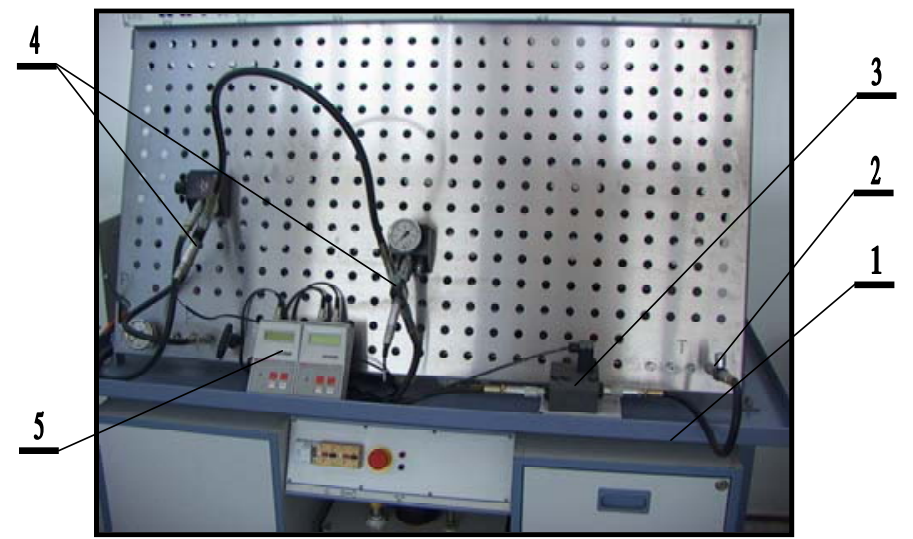

Fig. 4. Test rig of hydraulic losses measurment

\subsubsection{Measurement procedures}

1. Connecting the first hose (60 $\mathrm{cm}$ long) between the two pressure transducers,

2. Adjusting the throttle valve at fully opening position,

3. Switching the hydraulic pump of the main hydraulic test bench on, 
4. Recording the readings of the two display units of pressure drop across the hose and pump flow rate,

5. Changing the setting of the throttle valve to get a new value of pump flow rate, and then repeat step 4,

6. Repeating step 5 several times,

7. Repeating all previous steps from step 1 to step 6 for the second hose ( $110 \mathrm{~cm}$ long),

8. Repeating all previous steps from step 1 to step 6 for the two hoses connected together $(110 \mathrm{~cm}+60 \mathrm{~cm})$,

9. Plotting the recorded data and performing curve fitting by MATLAB program to get the mathematical model (simulation) of the hydraulic losses in each hose length.

\subsubsection{Obtained results}

Fig. (5), demonstrates the hose pressure losses versus pump flow rate of a connecting hose of $60 \mathrm{~cm}$ long. The obtained curve fitting by MATLAB program is:

$$
\Delta P=5.741 \times 10^{10} Q^{1.2954}
$$

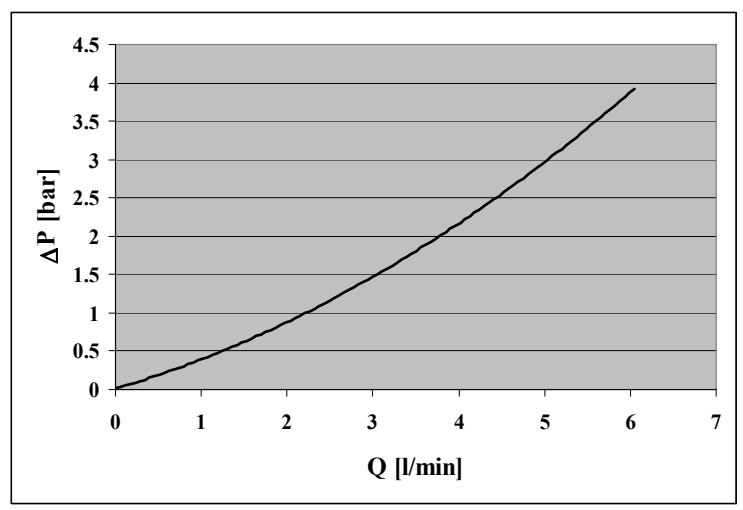

Fig. 5. Pressure losses in $60 \mathrm{~cm}$ hose

Fig. (6), demonstrates the hose pressure losses versus pump flow rate of a connecting hose of $110 \mathrm{~cm}$ long. The obtained curve fitting by MATLAB program is:

$$
\Delta \mathbf{P}=5.035 \times 10^{10} \mathbf{Q}^{1.2735}
$$

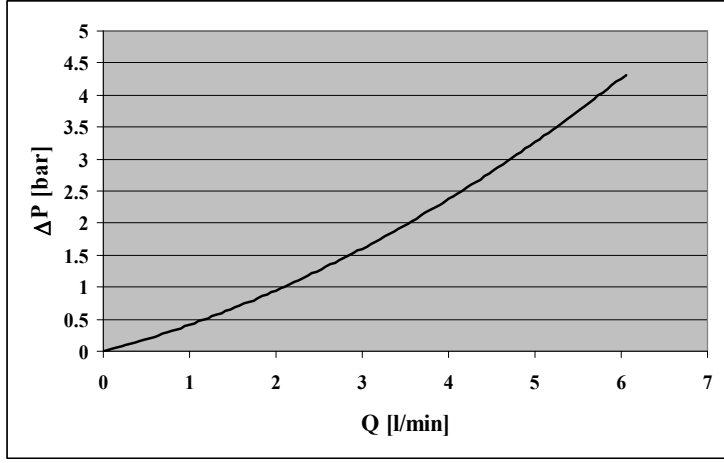

Fig. 6. Pressure losses in $110 \mathrm{~cm}$ hose 
Fig. (7), demonstrates the hose pressure losses versus pump flow rate of both a connecting hose of $60 \mathrm{~cm}$ long and a connecting hose of $110 \mathrm{~cm}$ long. The obtained curve fitting by MATLAB program is:

$$
\Delta \mathbf{P}=8.9125 \times 10^{10} \mathbf{Q}^{1.2753}
$$

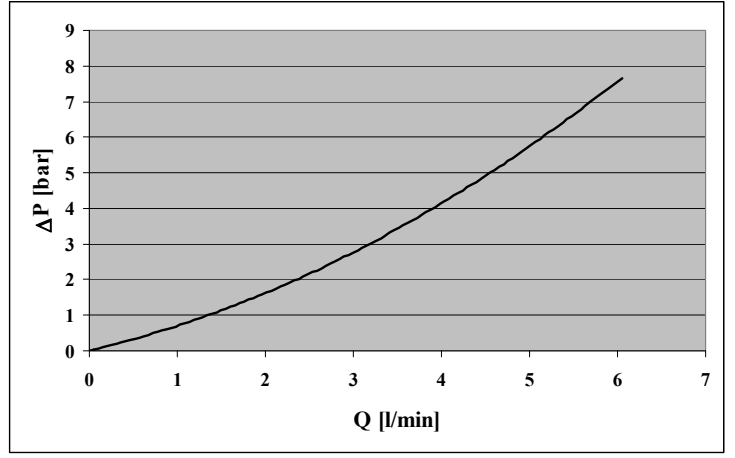

Fig. 7. Pressure losses in $170 \mathrm{~cm}$ hose

The power of flow rate $\mathbf{Q}$ in the previous relations varied from that are known for laminar and turbulent flow may be due to the effect of quick connections or may be due to that the flow is not fully developed.

\subsection{Measurement of transient pressure developed in the hydraulic cylinder chamber versus solenoid current}

The objective of this measurement is to be used in validation of the transient state of theoretically derived simulation model of the electro-hydraulic system. The developed transient pressure in hydraulic cylinder chamber has been measured at different solenoid currents. The cylinder is placed vertically, and the force applied to the cylinder is a tension force due to vertical load, so the pressure has been measured in the rod side chamber of the hydraulic cylinder, i.e. against load.

Experimental test rig is shown in Fig. (8). It consists of the following elements:

Hydraulic test bench (1), Pressure transducer at rod side of hydraulic cylinder(2), Direction proportional valve (3), Current regulator (4), Data acquisition, to record the pressure signal from pressure transducer (5), Hydraulic cylinder (6).

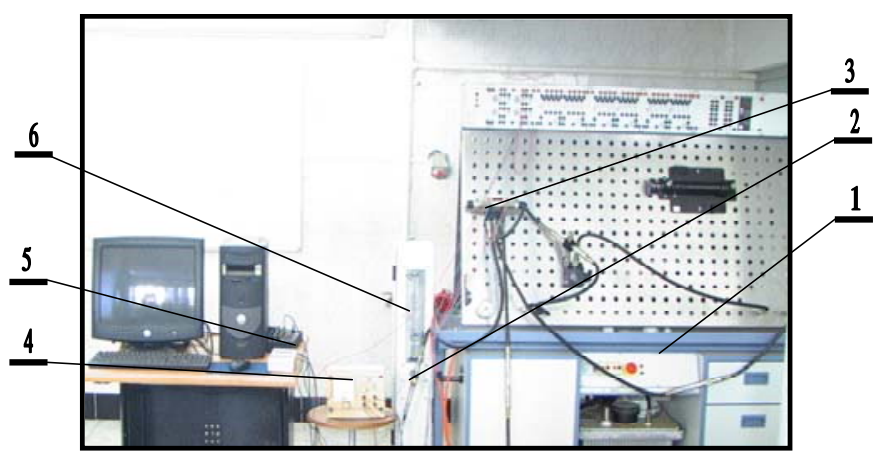

Fig. 8. Test rig of transient pressure measurement in a vertically loaded hydraulic cylinder 


\subsubsection{Measurement procedures}

1- Adjusting the relief valve at the maximum pressure in the hydraulic circuit (55 bar),

2- Switching on the pump of the hydraulic bench,

3- Actuating the cylinder to the fully extracted position,

4- Actuating the solenoid of the proportional valve by using the current regulator so that the hydraulic oil directs to the rod side of the cylinder causing rod retraction, and recording the pressure signal of the plugged transducer in the rod side chamber of the cylinder,

5- Plotting the acquired pressure data,

6- Returning the cylinder to its fully extracted position,

7- Repeating steps 4, 5 and 6 at different sittings of solenoid currents.

\subsubsection{Results}

The experiment has been performed at solenoid currents of 0.4, 0.6, and 0.8 Amperes. The transient pressure development in the rod side chamber of the vertically loaded hydraulic cylinder at different solenoid currents is presented in the figures below (Fig. (9) to Fig. (11)). It is observed that as the solenoid current increases the developed steady state pressure in the rod side chamber of the cylinder decreases. This is because when the solenoid current increases, the opening area of the proportional directional valve to the tank increases which leads to a reduction in the developed pressure in piston side chamber and that leads to the decrease of the pressure developed in the rod side chamber.

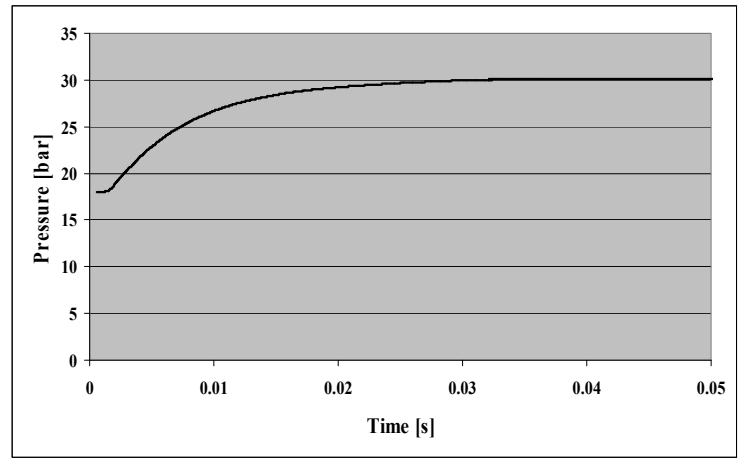

Fig. 9. Transient pressure at solenoid current of $0.4 \mathrm{~A}$

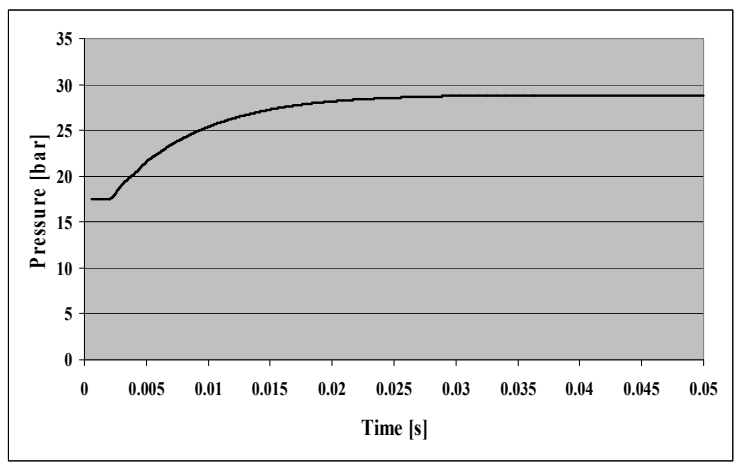

Fig. 10. Transient pressure at solenoid current of $0.6 \mathrm{~A}$

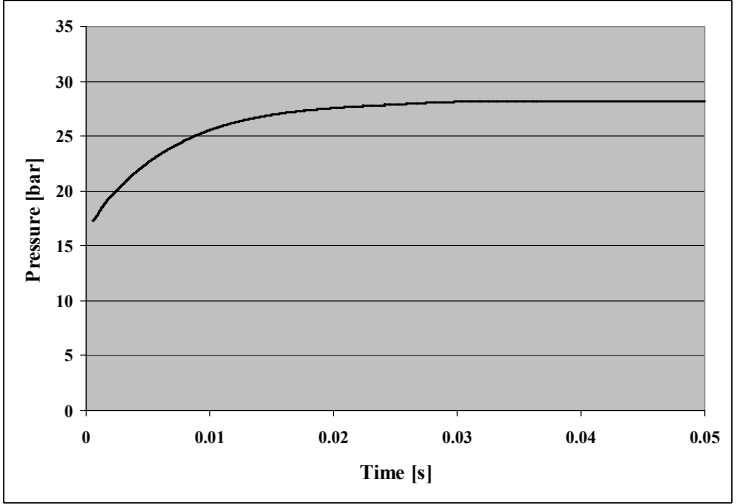

Fig. 11. Transient pressure at solenoid current of $0.8 \mathrm{~A}$ 


\section{Theoretical Investigations}

In order to obtain a simulation program for the electro-hydraulic system, each element of the system has been studied individually in order to obtain the mathematical equations which describe its operation. These equations have been plugged together into SIMULINK software in order to obtain a computer program simulating the electro-hydraulic system. The model has been validated by comparing the theoretically simulated parameters with the experimentally measured parameters of a corresponding real electro-hydraulic system in laboratory. The circuit diagram of the electro-hydraulic proportional system under simulation in shown in Fig. (12).

The electro-hydraulic circuit contains the following elements:

1. Oil tank;

2. Hydraulic gear pump;

3. Relief valve;

4. 4/3 electro-hydraulic proportional directional valve;

5. Vertical hydraulic cylinder (double acting single rod);

6. Connection hoses with quick junctions.

The hydraulic cylinder actuates a vertical load with variable weights. The flow rate directions are indicated in symbols, on the connection lines of the hydraulic system, for the purpose of building the mathematical models of all system elements.

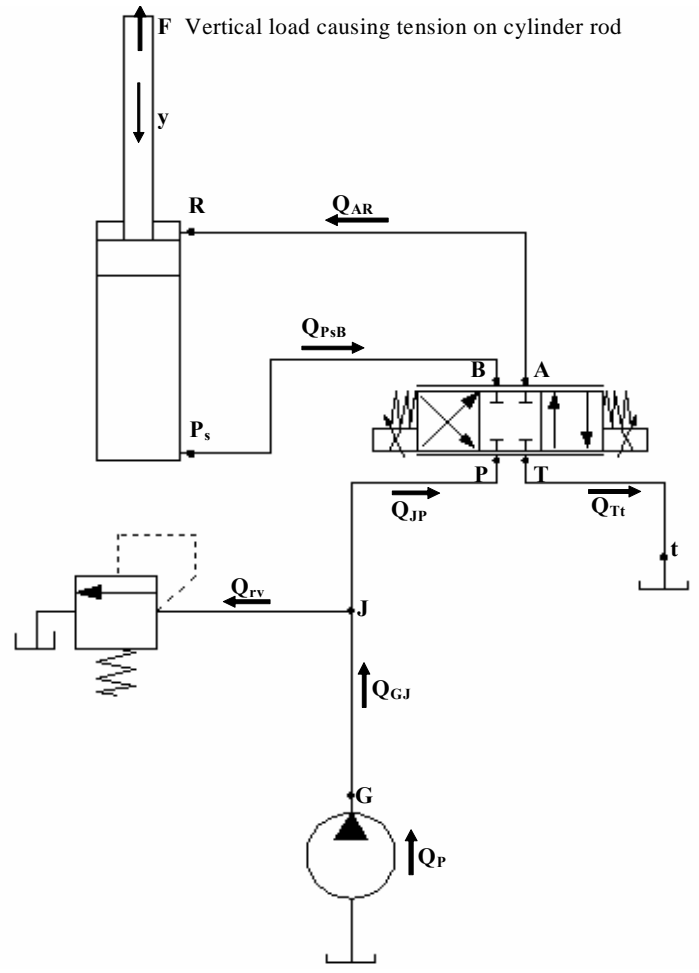

Fig. 12. Electro-hydraulic proportional system

The Details of obtaining mathematical models of all mentioned hydraulic elements in Fig. (12) could be inspected by referring to reference [4]. A brief of the obtained mathematical equations is shown in Table (1) below and the corresponding SIMULINK program is shown in Fig. (13). 
Table 1. Derived mathematical equations which simulate the electro-hydraulic proportional system and that are plugged into SIMULINK program

\begin{tabular}{|c|c|}
\hline Hydraulic Element & Corresponding Mathematical Equation \\
\hline Gear pump & $Q_{p}=Q_{t h}-7 \times 10^{-13} P_{G}$ \\
\hline Short hoses $(60 \mathrm{~cm})$ & $\Delta P=5.741 \times 10^{10} Q^{1.2954}$ \\
\hline Long hoses $(110 \mathrm{~cm})$ & $\Delta P=5.035 \times 10^{10} Q^{1.2735}$ \\
\hline Two integrated hoses $(170 \mathrm{~cm})$ & $\Delta P=8.9125 \times 10^{10} Q^{1.2753}$ \\
\hline \multirow[t]{2}{*}{ Relief valve poppet motion } & $m_{p} \frac{d^{2} z}{d t^{2}}+f_{r} \frac{d z}{d t}+k_{r}\left(z+z_{0}\right)=p \cdot A_{p}+F_{\text {seat }}$ \\
\hline & $\mathbf{F}_{\text {seat }}=\mathbf{k}_{\mathrm{s}} \cdot \mathbf{z}_{\mathbf{0}}$ \\
\hline Flow rate throughout relief valve & $Q_{r v}=C_{d} A_{p} \sqrt{\frac{2\left(p-p_{t}\right)}{\rho}}$ \\
\hline Directional valve spool motion & $F_{s}=m{ }_{s} \frac{d^{2} x}{d t^{2}}+f_{s} \frac{d x}{d t}+k x$ \\
\hline $\begin{array}{c}\text { Flow rate through directional valve } \\
\text { orifice a }\end{array}$ & $Q_{a}=C_{d} A_{b}(x) \sqrt{\frac{2\left(P_{B}-P_{t}\right)}{\rho}}$ \\
\hline $\begin{array}{l}\text { Flow rate through directional valve } \\
\text { orifice b }\end{array}$ & $Q_{b}=C_{d} A_{b}(x) \sqrt{\frac{2\left(P_{s}-P_{B}\right)}{\rho}}$ \\
\hline $\begin{array}{c}\text { Flow rate through directional valve } \\
\text { orifice c }\end{array}$ & $Q_{c}=C_{d} A_{c}(x) \sqrt{\frac{2\left(P_{s}-P_{A}\right)}{\rho}}$ \\
\hline $\begin{array}{c}\text { Flow rate through directional valve } \\
\text { orifice d }\end{array}$ & $Q_{d}=C_{d} A_{d}(x) \sqrt{\frac{2\left(P_{A}-P_{t}\right)}{\rho}}$ \\
\hline $\begin{array}{c}\text { Flow rate in rod side chamber of } \\
\text { hydraulic cylinder }\end{array}$ & $Q_{\mathrm{AR}}-a \frac{d y}{d t}-Q_{i}-Q_{e}-\frac{\left(V_{R}+a y\right)}{B} \times \frac{d p_{R}}{d t}=0$ \\
\hline $\begin{array}{l}\text { Flow rate in piston side chamber of } \\
\text { hydraulic cylinder }\end{array}$ & $A \frac{d y}{d t}+Q_{i}-Q_{p s B}-\frac{\left(V_{p s}-A y\right)}{B} \times \frac{d p_{p s}}{d t}=0$ \\
\hline $\begin{array}{l}\text { Piston and rod motion of hydraulic } \\
\text { cylinder }\end{array}$ & $a \cdot p_{R}-A \cdot p_{p s}=m_{c} \frac{d^{2} y}{d t^{2}}+f_{c} \frac{d y}{d t}+F$ \\
\hline Continuity equation at point $\mathrm{G}$ & $Q_{p}-Q_{G J}=\frac{V}{B} \times \frac{d P_{G}}{d t}$ \\
\hline $\begin{array}{l}\text { Flow rate between points of connections } \\
\qquad \mathrm{G} \text { and } \mathrm{J}\end{array}$ & $Q_{G J}=4.94831 \times 10^{-9}\left(P_{G}-P_{J}\right)^{1 / 1.2954}$ \\
\hline Continuity equation at point $\mathrm{J}$ & $Q_{G J}-Q_{r v}-Q_{J P}=\frac{V}{B} \times \frac{d P_{J}}{d t}$ \\
\hline $\begin{array}{l}\text { Flow rate between points of connections } \\
\mathrm{J} \text { and } \mathrm{P}\end{array}$ & $Q_{J P}=4.94831 \times 10^{-9}\left(P_{J}-P_{P}\right)^{1 / 1.2954}$ \\
\hline
\end{tabular}


Table 1. (continued) Derived mathematical equations

\begin{tabular}{|c|c|}
\hline Continuity equation at point $\mathrm{P}$ & $Q_{J P}-Q_{b}-Q_{c}=\frac{V}{B} \times \frac{d P_{P}}{d t}$ \\
\hline Continuity equation at point $\mathrm{A}$ & $Q_{c}-Q_{d}-Q_{A R}=\frac{V}{B} \times \frac{d P_{A}}{d t}$ \\
\hline $\begin{array}{l}\text { Flow rate between points of connections } \\
\qquad \mathrm{A} \text { and } \mathrm{R}\end{array}$ & $Q_{A R}=3.94809 \times 10^{-9}\left(P_{A}-P_{R}\right)^{1 / 1.2735}$ \\
\hline $\begin{array}{l}\text { Flow rate between points of connections } \\
\qquad \mathrm{P}_{\mathrm{s}} \text { and } \mathrm{B}\end{array}$ & $Q_{\mathrm{PsB}}=2.59289 \times 10^{-9}\left(\mathrm{P}_{\mathrm{Ps}}-\mathrm{P}_{\mathrm{B}}\right)^{1 / 1.2753}$ \\
\hline Continuity equation at point B & $Q_{P s B}+Q_{b}-Q_{a}=\frac{V}{B} \times \frac{d P_{B}}{d t}$ \\
\hline Continuity equation at point $\mathrm{T}$ & $Q_{\mathrm{a}}+Q_{\mathrm{d}}-Q_{\mathrm{T} 3}=\frac{V}{B} \times \frac{\mathbf{d P}}{\mathbf{d t}}$ \\
\hline $\begin{array}{l}\text { Flow rate between points of connections } \\
\qquad \mathrm{T} \text { and } \mathrm{t}\end{array}$ & $Q_{T t}=2.59289 \times 10^{-9}\left(P_{T}-P_{3}\right)^{1 / 1.2753}$ \\
\hline Tank pressure & $\mathbf{P}_{\mathrm{t}}=\mathbf{0}$ \\
\hline
\end{tabular}

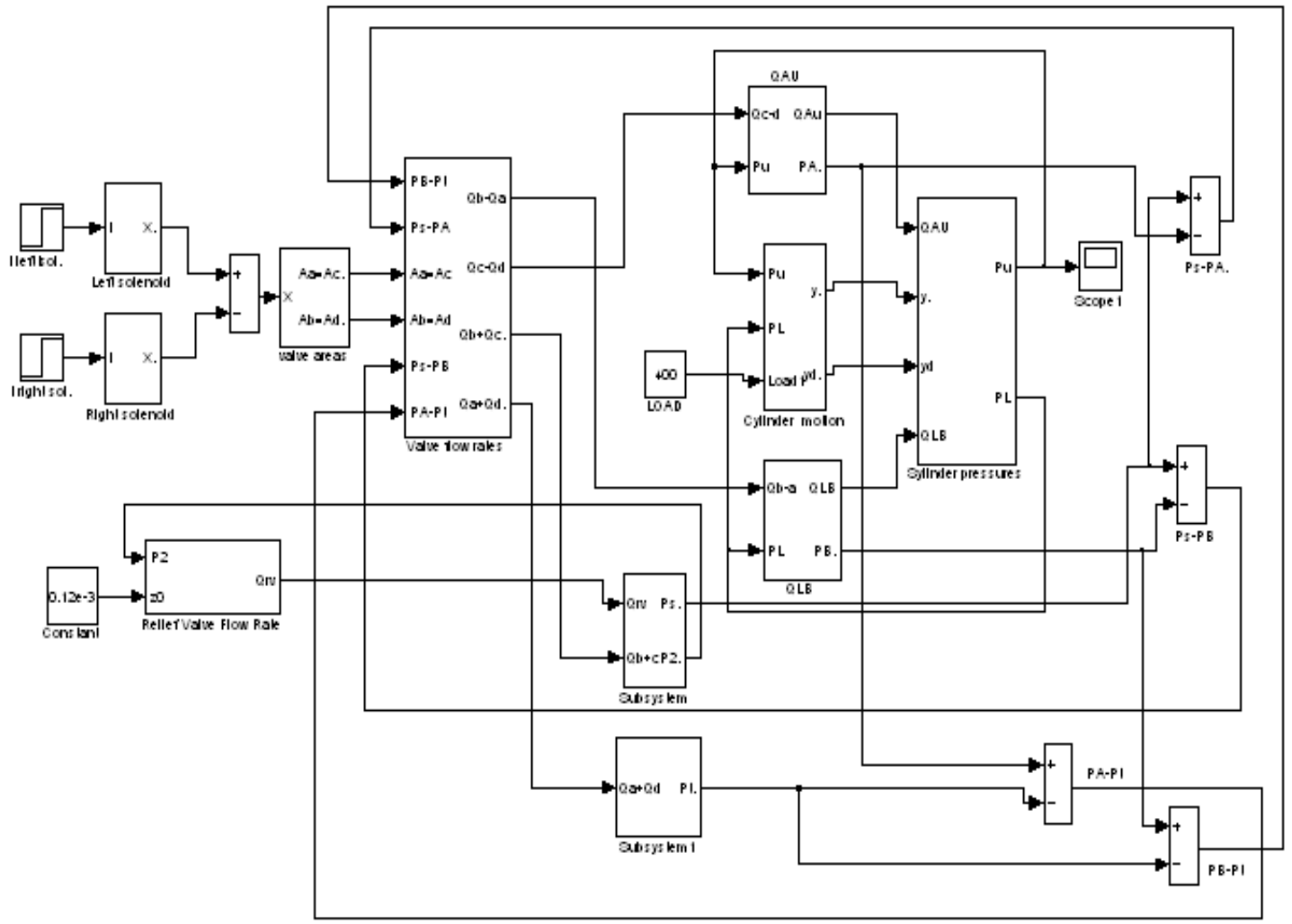

Fig. 13. SIMULINK Modeling of the electro-hydraulic system with proportional valve 


\section{Verification of Simulation Program}

The results of experimental measurements for the transient state of the electro-hydraulic proportional system have been used to validate the theoretical simulation model. The simulation program has been run at various values of proportional solenoid electric currents (0.6 A, and $0.8 \mathrm{~A}$ ) and the transient pressure in the rod side chamber of the hydraulic cylinder has been simulated versus time and compared with the corresponding experimental measurement. Fig. (14) and Fig. (15) show the comparison between the simulated and the measured transient pressures in the rod side chamber of the hydraulic cylinder at 0.6 , and 0.8 Ampere respectively. It is observed that there are relatively small deviations in the transient period of the two curves. This may be referred to neglecting the dynamic effect of the hydraulic oil when modeling the connecting hoses, which affects the transient state of the system.

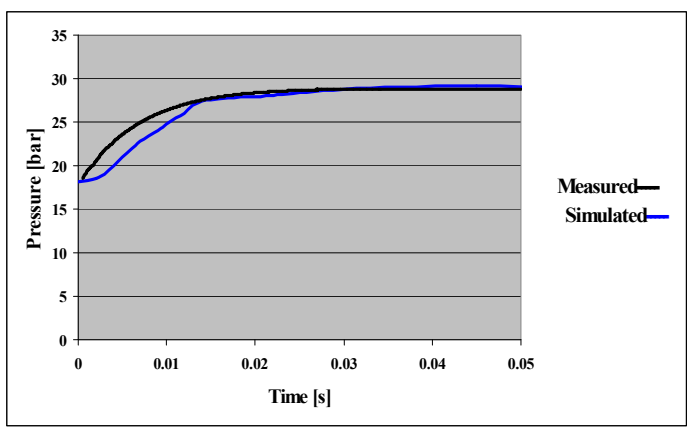

Fig. 14. Measured and simulated developed pressure in rod side chamber of the cylinder at solenoid current of $0.6 \mathrm{~A}$.

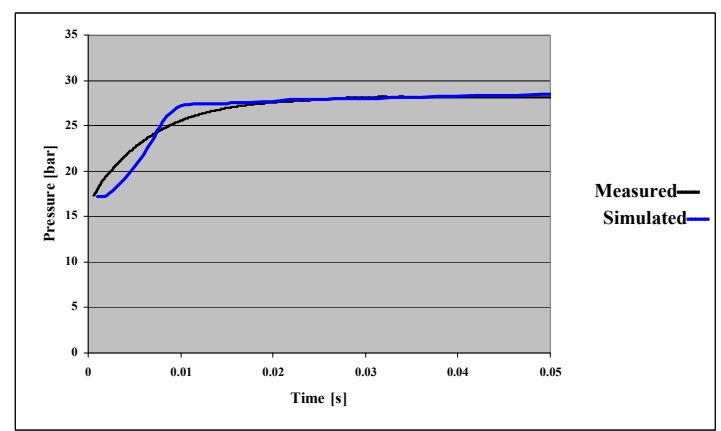

Fig. 15. Measured and simulated transient pressure in rod side chamber of the cylinder at solenoid current of $0.8 \mathrm{~A}$.

\section{Dynamic Performance of Simulated Electro-hydraulic System}

The simulation program of the electro-hydraulic proportional system has been used to investigate the dynamic performance of the system when working at different operating conditions. It has been operated to simulate the performance in the following cases:

1. System operation at different values of orifice widths of proportional valves (which simulate the size exchange of proportional valve or change in its geometry due to wear.

2. System operation with increase in the internal clearance of cylinder piston (which simulates the aging of hydraulic cylinder).

3. System operation with increase in internal clearance of the spool of proportional valve (which simulates the aging of proportional valve).

\subsection{Operation at different widths of the proportional valve orifice}

The system has been run at different values of valve orifice widths, $\mathrm{w}=0.1 ; 0.2 ; 1.0$; and 2.0 $\mathrm{mm}$, while the other system operating parameters have been kept constant; the solenoid current at 0.8 Ampere, the pump flow rate at 6.05 liter/min, and the cylinder load at $400 \mathrm{~N}$. The pressure in the rod side chamber of hydraulic cylinder and the velocity of the load have been plotted versus time in order to study the dynamic behavior of the system at different values of valve orifice widths. The time signal of transient pressure response in the rod side of hydraulic cylinder and the corresponding load velocity at different values of orifice widths have been plotted in Fig. (16) and Fig. (17), respectively. In order to study the dynamic performance of the system, the settling time, $\mathbf{t}_{\mathbf{s}}$, and the percentage over shooting, $\delta$, have 
been calculated and plotted for the pressure response in Fig. (18) and Fig. (19), and for the corresponding load velocity in Fig. (20) and Fig. (21).

Fig (18) shows that the settling time of the developed pressure in the rod side chamber of the cylinder increases as the orifice width increases because of the development of pressure over shoot. As the orifice width increases, the pressure over shoot becomes sharper, as shown in Fig. (19), so the settling time decreases again. In case of load velocity, the settling time increases for the orifice width ranges from $0.1 \mathrm{~mm}$ to value less than $0.5 \mathrm{~mm}$ because the over shoot becomes wider. At larger orifice widths above $0.5 \mathrm{~mm}$ the settling time decreases as the load velocity increases because the system becomes over damped system.

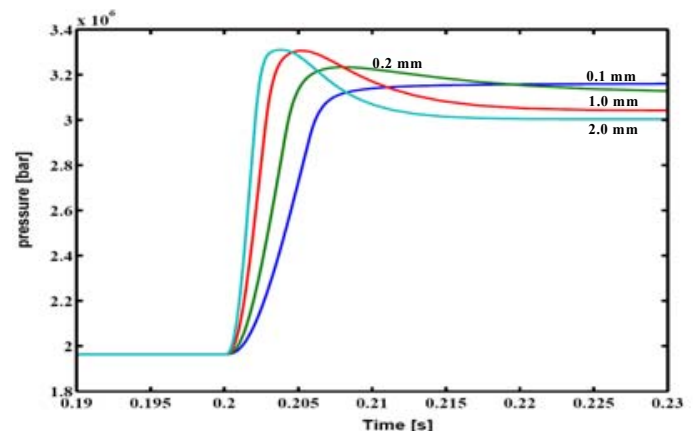

Fig. (16) Pressure response in the rod side chamber of cylinder at different values of valve orifice widths.

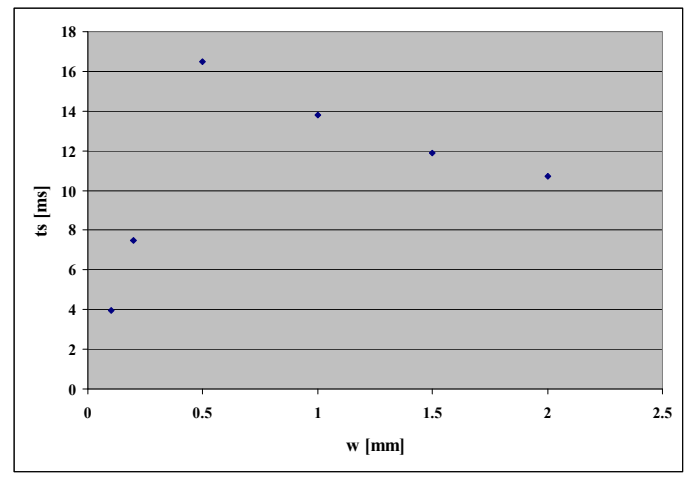

Fig. 18. Settling time, $t_{s}$, of pressure in rod side chamber of hydraulic cylinder versus valve orifice widths

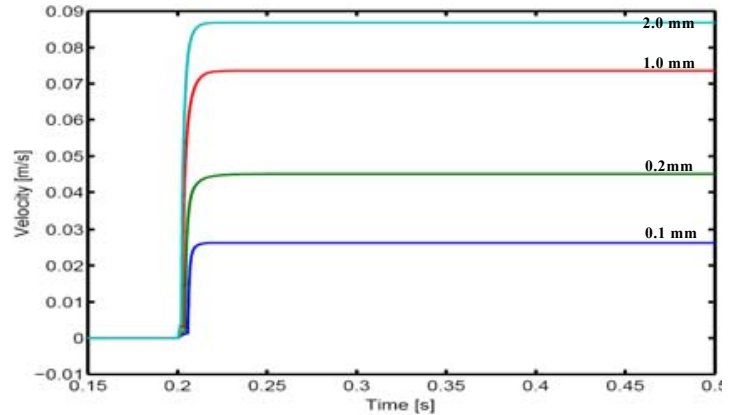

Fig. (17) Velocity response of the cylinder load at different values of valve orifice widths.

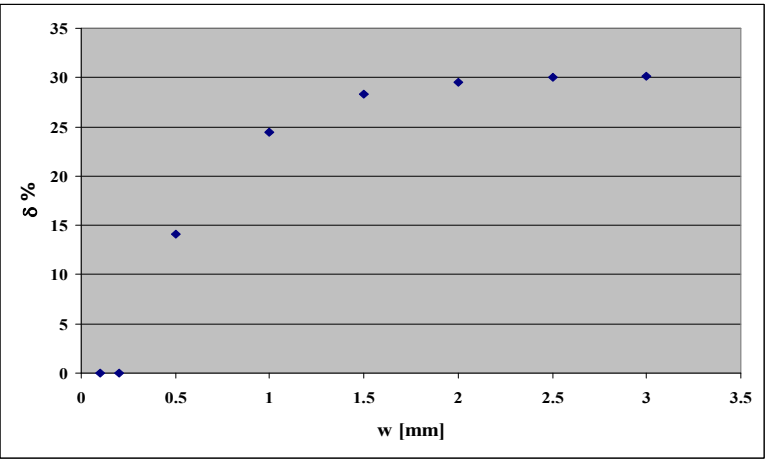

Fig. 19. Percentage over shooting, $\delta$, of pressure in rod side chamber of hydraulic cylinder versus valve orifice widths 


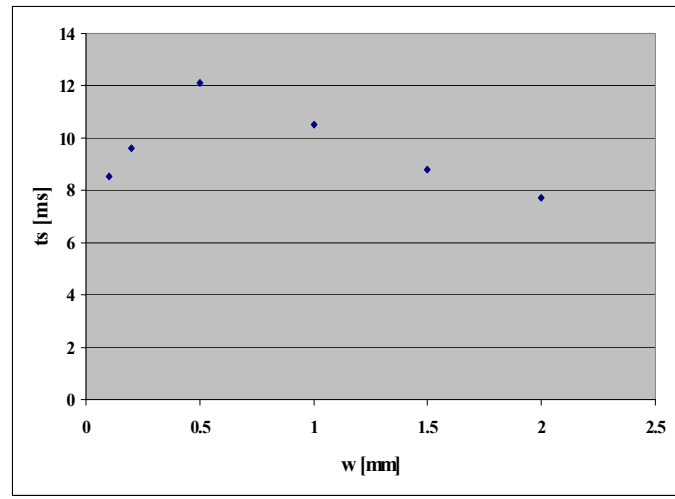

Fig. 20. Settling time, $t_{s}$, of piston velocity versus valve orifice widths

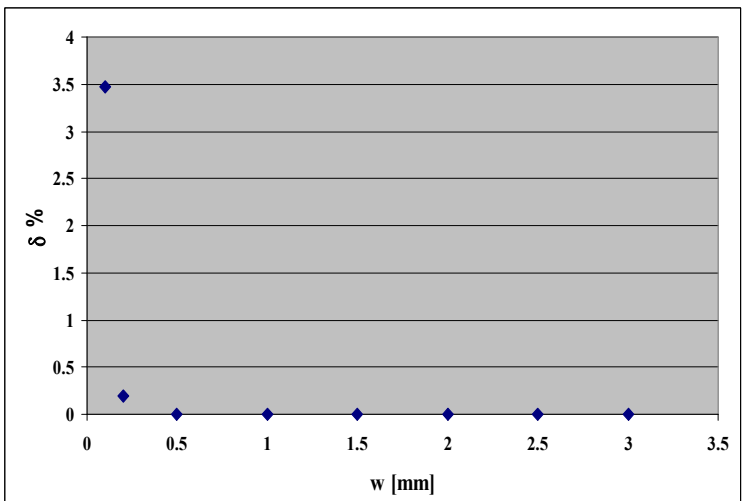

Fig. 21. Percentage over shooting, $\delta$, of load velocity versus valve orifice widths

\subsection{Operation at different piston clearances of the hydraulic cylinder}

The simulation computer program of the electro-hydraulic proportional system has been run at different values of internal cylinder clearances of $7 \mu \mathrm{m}, 10 \mu \mathrm{m}, 50 \mu \mathrm{m}$ and $100 \mu \mathrm{m}$, to predict the effect of increasing of the internal clearance between the piston and cylinder (which simulates the cylinder ageing) on the dynamic performance of the electro-hydraulic system. Fig. (22) shows the transient response of pressure in the rod side chamber of the cylinder and Fig. (23) shows the transient velocity of the load versus piston clearances. It is obvious that when the piston clearance increases the velocity of the piston decreases which may be attributed to the increase of internal leakage. Consequently the friction force decreases (which has been modulated by the term $f_{c} \frac{d y}{d t}$ in the modeling equation of piston motion in Table (1)) and the pressure $\left(\boldsymbol{P}_{\boldsymbol{R}}\right)$ required to move the load decreases. Fig. (24) and Fig. (25), show the settling time and percentage overshoot of the developed pressure in the rod side chamber of the hydraulic cylinder versus piston clearances, respectively. Noticing that as the piston clearance increases, the percentage overshoot increases, that is because of the decreasing of pressure in the rod side chamber of the hydraulic cylinder as a result of increasing in piston clearance. The increase of pressure overshoot leads to the increase of settling time. Fig. (26) and Fig. (27), show the settling time and percentage overshoot of the transient response of the load velocity versus piston clearances. It is noticed that as the piston clearance increases, the internal leakage increases too, so the time required to reach the steady state velocity increases. It is also cleared from fig.(27) that there is no over shooting developed during operation. 


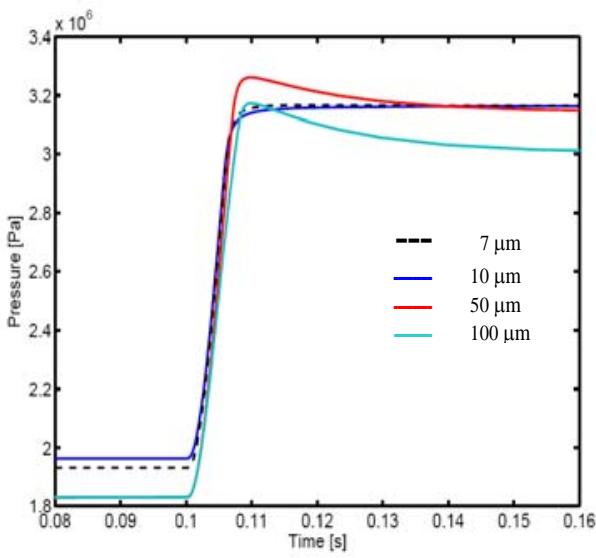

Fig. 22. Transient pressure response for different piston clearances

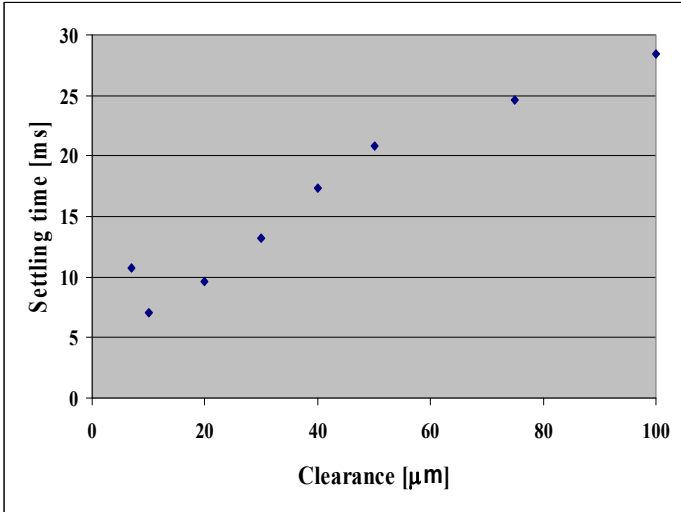

Fig. 24. Settling time of transient pressure for different piston clearances

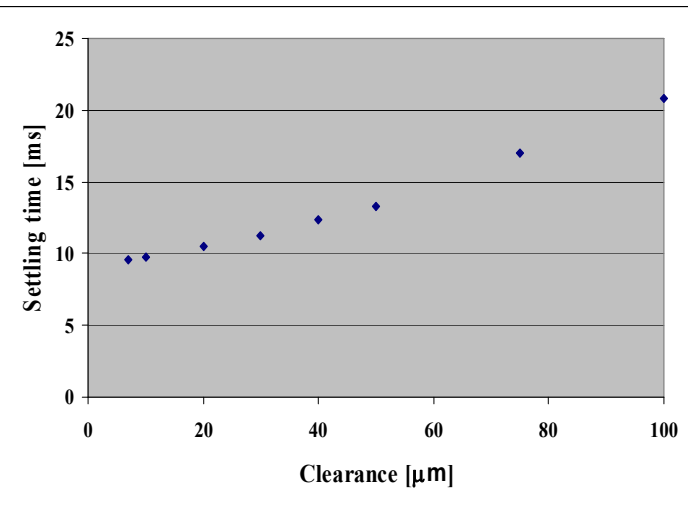

Fig. 26. Settling time of load velocity for different piston clearances

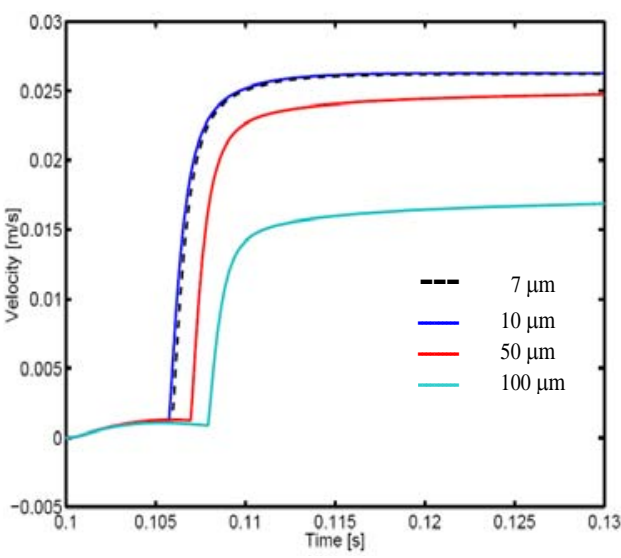

Fig. 23. Transient velocity of the load for different piston clearances

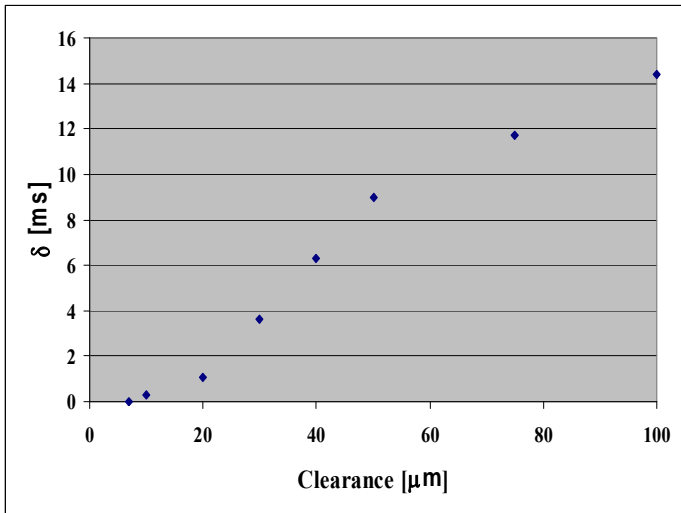

Fig. 25. Percentage over shooting of transient pressure for different piston clearances

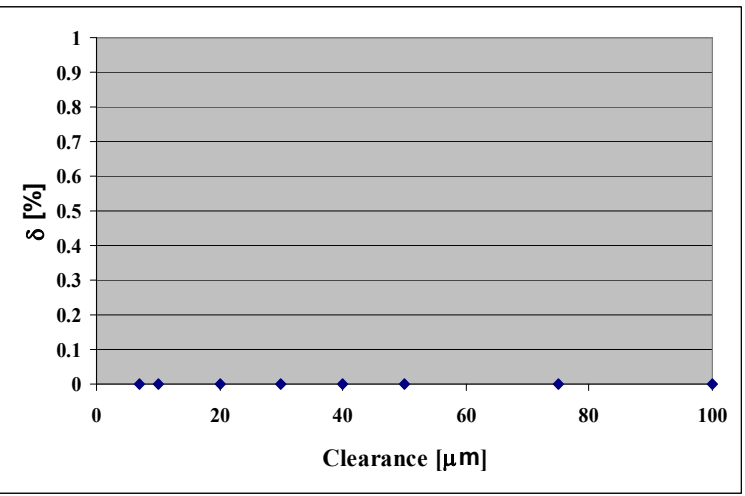

Fig. 27. Percentage over shooting of load velocity for different piston clearances 


\subsection{Operation at different internal clearance of the directional valve spool}

To predict the effect of spool clearance increase (which simulates the ageing of the directional proportional valve) on the dynamic behavior of electro-hydraulic proportional system the simulation computer program of the electro-hydraulic proportional system has been operated at different values of spool clearances with values; $1 \mu \mathrm{m} ; 10 \mu \mathrm{m} ; 100 \mu \mathrm{m}$; and $1000 \mu \mathrm{m}$. The transient pressure in the rod side chamber of the hydraulic cylinder and the corresponding load velocity at those mentioned values of spool clearances have been plotted in Fig. (28) and Fig. (29), respectively. The settling time and percentage overshoot of the developed pressure in the rod side chamber versus spool clearances have been plotted in Figs. (30) and (31). As the spool clearance increases, the settling time leads to increase in percentage overshoot increase. The increase in spool clearance causes increase in internal leakage of the directional proportional valve so the required time for the piston to reach the steady state velocity increases. The settling time and percentage overshoot of the load velocity versus spool clearances have been calculated and plotted in Fig. (32) and Fig. (33), respectively. From those figures, it is obvious that as the spool clearance increases the internal leakage in the directional proportional valve increases, so the directed flow rate to the cylinder chamber decreases and consequently the cylinder piston velocity decreases and the developed pressure in cylinder chamber decreases too.

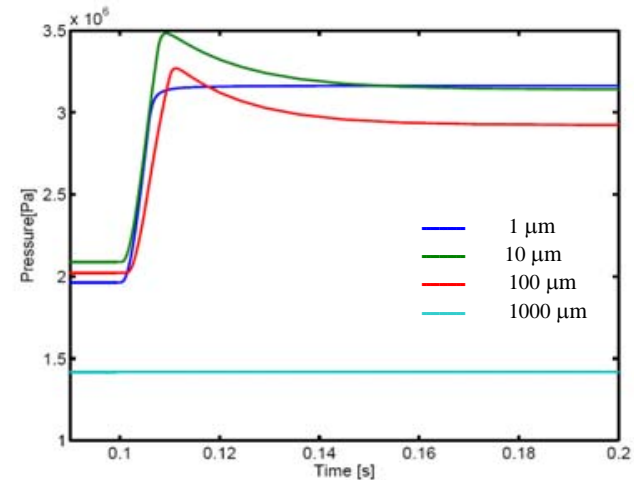

Fig. 28. Transient pressure response for different spool clearances

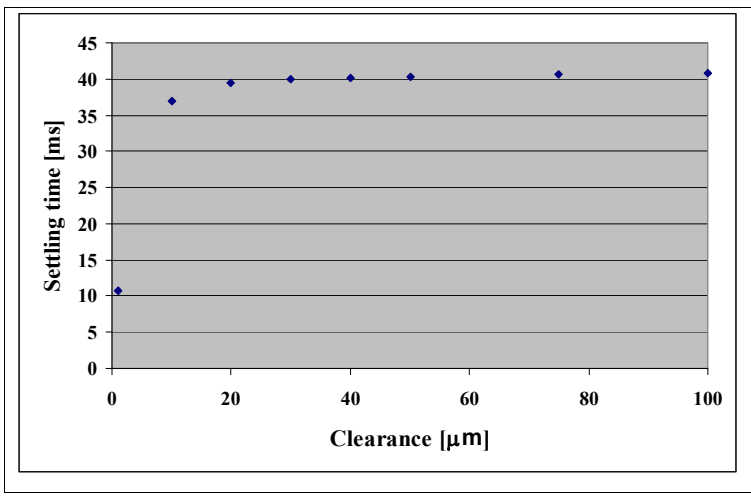

Fig. 30. Settling time of transient pressure for different spool clearances

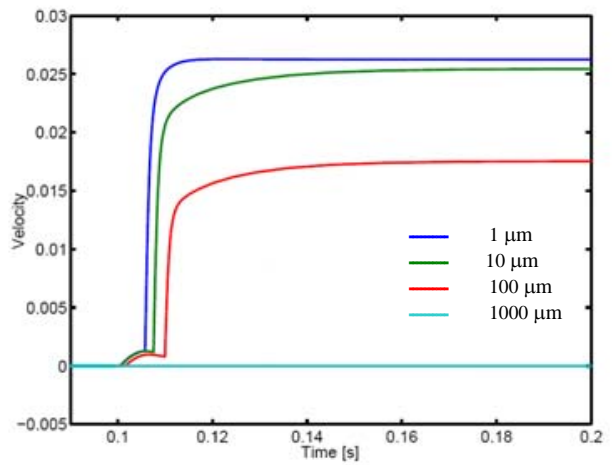

Fig. 29. Transient velocity of the load for different spool clearances

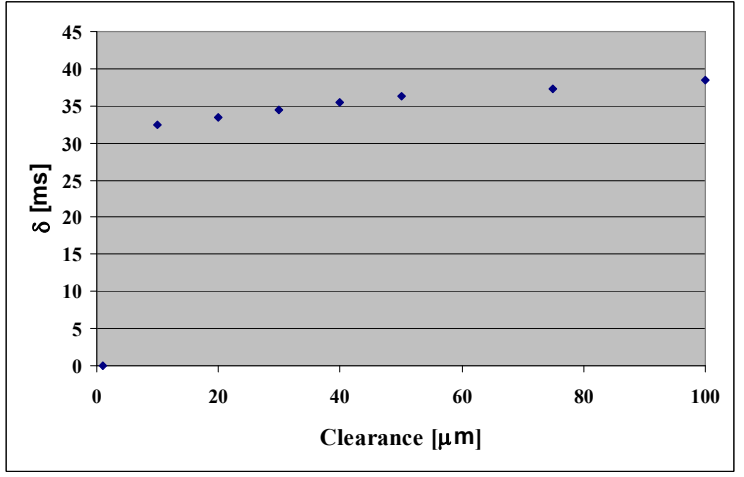

Fig. 31. Percentage over shooting of transient pressure for different spool clearances 


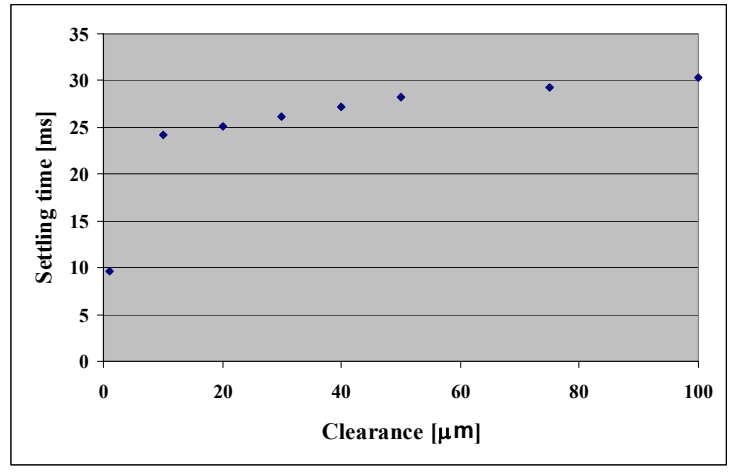

Fig. 32. Settling time of load velocity for different spool clearances

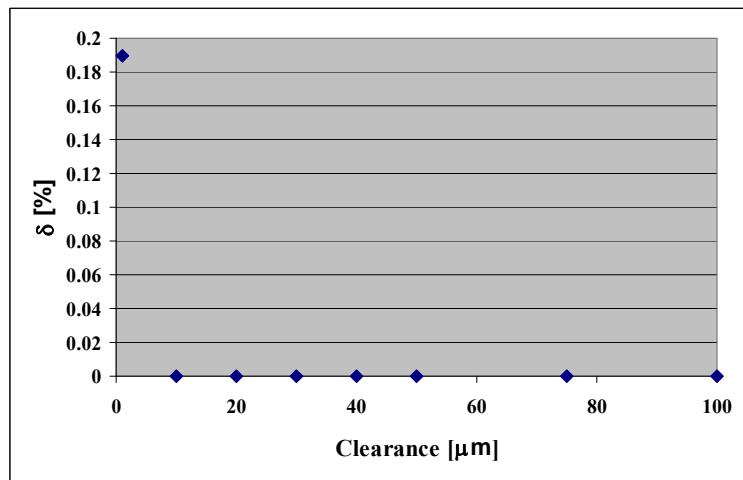

Fig. 33. Percentage over shooting of load velocity for different spool clearances

\section{Conclusion}

The invention of proportional valve has been filled the great gap between solenoid valve and servo valve. Nowadays the proportional valves are used extensively in wide applications. The present work was directed to study the dynamic performance of an electro-hydraulic system incorporates an electro-hydraulic proportional directional control valve. This valve was used to control the flow direction and flow rate simultaneously. The following have been concluded:

1. The program was built by converting the mathematical models of the system elements to a computer program in SIMULINK environment.

2. The mathematical models of some elements were difficult to be obtained theoretically because of the lack in information of their effective parameters. Therefore, experimental measurements of their characteristic parameters were carried out to get their mathematical relations by curve fitting technique.

3. For validation of the simulation model, an experiment was used to measure the transient pressure in cylinder rod side chamber versus time. Then, comparison of the experimental measured values with the corresponding theoretical results was carried out from the simulation model to assure program validation.

4. The validated model was used to predict the dynamic performance of the electrohydraulic proportional system when the system works under different operating conditions (different valve orifice widths, different piston clearances of hydraulic cylinder, and different spool clearances of proportional valve). The results are as follows:

i. As the widths of the valve orifices increases, the settling time of the developed pressure in the rod side chamber of hydraulic cylinder increases because of the development of pressure over shoot. As the orifice width increases, the pressure over shoot becomes sharper, so the settling time decreases again. The increase of pressure overshoot leads to increase in settling time, so the system becomes under damped due to development of the pressure overshoot.

ii. As the piston clearance increases the developed pressure in the rod side chamber decreases and the pressure overshoot is developed so, the system becomes under damped.

iii. As the internal clearance of the directional valve spool increases the developed pressure in the rod side chamber of hydraulic cylinder decreases and the pressure overshoot is developed so, the system becomes under damped. 


\section{References}

[1] Lai-JiingYih; Chen-YuanRong, 1992 “Adaptive Flow Rate Control Of A Hydraulic Proportional Valve”, JSME Int J, Ser 3, v 35, n 4, Dec 1992, p 582-590, ISSN:09148825.

[2] Li-Li; Wang-XiZhen; Yan-ZhaoDa; Ju-YuSheng; Dong-YaoQing, 2004 "Modeling Of Solenoid-Actuated Valve System”, Neiranji Gongcheng/Chinese Internal Combustion Engine Engineering, v 25, n 4, August 2004, p 11-14+19, ISSN:1000-0925.

[3] Maiti R.; Saha, R.; Watton, J., 2002 "The Static and Dynamic Characteristics of A Pressure Relief Valve with A Proportional Solenoid-Controlled Pilot Stage", Department of Mechanical Engineering Indian Institute of Technology, Kharagpur 721 302, India.

[4] Menshawy, T.M., "Investigation of Dynamic Behavior of an Electrohydraulic Proportional System”, M.Sc. Thesis, Military Technical College, Cairo, Egypt, 2006.

[5] Menshawy, T.M., Lotfy, A.H., 2008 "Theoretical and Experimental Investigations of Dynamic Behavior of an Electro-Hydraulic Directional Proportional Valve", $12^{\text {th }}$ International Conference On Applied Mechanics And Mechanical Engineering, pp. 165 to 177,volume1, MTC, Cairo, Egypt.

[6] Mourre, D.P., Burton, R.T., Bitner, D., and Ukrainetz, P.R., 1999 “A Technique To Estimate Some Valve Parameters In A Proportional Valve”, Bath Workshop on Power Transmission and Motion Control, pp. 3-5 to -13.

[7] Rabie G., 2003 ”Aircraft Hydraulic and Pneumatic systems”

[8] Sorli Massimo; Figliolini Giorgio and Pastorelli Stefano, "Dynamic Model and Experimental Investigation of a Pneumatic Proportional Pressure Valve", IEEE/ASME Transactions on Mechatronics v9, Department of Mechanics Polytechnic in Torino, Italy, March 2004.

[9] Vaughan, N. D.; Gamble, J, B., 1990 "Modelling and Simulation of A Proportional Solenoid Valve", American Society of Mechanical Engineers (Paper). Publ by ASME, New York, NY, USA, 1990, WA/FPST, pp 7-11, ISSN: 0402-1215.

[10] Yang-QingJun; Bao-Gang; Nie-BoXun; Wang-ZuWen, 2001 "Modeling Of Pneumatic Cylinder Controlled By Electronic Proportional Directional Valve", Harbin Gongye Daxue Xuebao/Journal of Harbin Institute of Technology, v 33, n 4, August 2001, p 495-498, ISSN:0367-6234. 